\title{
Dietary plasma proteins attenuate the innate immunity response in a mouse model of acute lung injury
}

\author{
Mònica Maijó ${ }^{1}$, Lluïsa Miró ${ }^{1}$, Javier Polo ${ }^{2}$, Joy Campbell ${ }^{3}$, Louis Russell ${ }^{3}$, Joe Crenshaw ${ }^{3}$, Eric Weaver ${ }^{4}$, \\ Miquel Moretó ${ }^{1}$ and Anna Pérez-Bosque ${ }^{1,2 *}$ \\ ${ }^{1}$ Group of Physiology and Experimental Nutrition, Department of Physiology, Faculty of Pharmacy, Nutrition and Food \\ Safety Research Institute, University of Barcelona, Avinguda de Joan XXIII s/n, E-08028, Barcelona, Spain \\ ${ }^{2} A P C$ Europe S.A., Granollers, Spain \\ ${ }^{3} A P C$, Inc., Ankeny, IA, USA \\ ${ }^{4}$ Proliant Health and Biologicals, Ankeny, IA, USA
}

(Received 14 December 2010 - Revised 10 May 2011 - Accepted 6 June 2011 - First published online 12 September 2011)

\section{Abstract}

We examined whether oral plasma protein supplements affect the innate immune response in a model of acute lung inflammation. Mice were fed diets supplemented with $8 \%$ spray-dried plasma (SDP) or $2 \%$ plasma Ig concentrate (IC) from day 19 (weaning) until day 34 . The mice were challenged with intranasal lipopolysaccharide (LPS) at day 33 (and killed $24 \mathrm{~h}$ later for cytokine and leucocyte analyses) or at day 34 (and killed $6 \mathrm{~h}$ later for cytokine determinations). In bronchoalveolar lavage fluid (BALF), LPS increased the number of leucocytes by twenty-sevenfold, an effect that was partly prevented by both SDP and IC, and by twentyfold the percentage of activated monocytes, which was partly prevented by SDP. In the lung tissue, LPS increased the infiltrated leucocytes, and this effect was prevented in part by SDP. In unchallenged mice, both SDP and IC diets reduced the percentage of resident neutrophils and monocytes $(P<0.05)$. In the blood, both SDP and IC completely prevented LPS-dependent monocyte activation $\left(\mathrm{CD}_{14}{ }^{+} ; P<0.05\right)$. LPS dramatically increased the concentration of cytokines (TNF- $\alpha$, IL- $1 \alpha$, IL- 6 , granulocyte-macrophage colony-stimulating factor and granulocyte colony-stimulating factor) and chemokines (CXCL1, CCL2, CCL3 and CCL4) in BALF. The acute response of cytokine production was reduced by $20-80 \%$ by both SDP and IC. For chemokines, plasma supplements had no effect on LPS-induced CXCL1 expression but significantly reduced CCL2, CCL3 and CCL4 production $(P<0 \cdot 05)$. The results support the view that dietary plasma proteins can be used to attenuate endotoxin-associated lung inflammation.

Key words: Spray-dried animal plasma: Ig concentrate: Lipopolysaccharide

Acute lung injury is the result of the host response to either inhaled or endogenous noxious agents and is characterised by the activation of nasal and bronchoalveolar-associated lymphoid tissue. Since lungs are constantly exposed to a large number of micro-organisms and provide a common entry route for pathogens into the body, lung infection is one of the most frequent causes of morbidity and death in humans $^{(1)}$. The inflammation cascade is initiated by the innate immune system, in which neutrophils have a key role in the inflammatory response as they contribute to the recruitment, activation and programming of antigen-presenting cells $^{(2)}$. Furthermore, they generate chemotactic signals that attract monocytes and dendritic cells ${ }^{(3)}$.

Enteral nutrition has a role in the prevention or amelioration of inflammatory responses in systemic mucosae. Dietary lycopene, a carotenoid with a powerful antioxidant capacity, can decrease eosinophilic infiltrates and reduce Th2 cytokine responses from lymph nodes, in a mouse model of allergic airway disease ${ }^{(4)}$. Dietary supplementation with amino acids such as glycine ${ }^{(5)}$ and tryptophan ${ }^{(6)}$ moderates lung inflammation, while dietary EPA and $\gamma$-linolenic acid reduce the risk of mortality in patients with acute respiratory distress syndrome $^{(7)}$. Traditional Chinese formulae ${ }^{(8,9)}$ have also been shown to be effective in the treatment of acute inflammation in mice challenged with lipopolysaccharide (LPS).

The possible mechanisms for such a therapeutic action are not well understood. In some cases, the effects are attributed to the absorbed nutrients acting at extra-intestinal tissues, as is the case of antioxidant molecules, that once absorbed in the small intestine, reach the lung, where they prevent or

Abbreviations: BALF, bronchoalveolar lavage fluid; GALT, gut-associated lymphoid tissue; G-CSF, granulocyte colony-stimulating factor; GM-CSF, granulocyte-macrophage colony-stimulating factor; IC, Ig concentrate; iNOS, inducible NO synthase; LPS, lipopolysaccharide; SDP, spray-dried plasma. 
reduce oxidative processes ${ }^{(4)}$. In others, the mechanism is indirect, involving activation of new mediators that eventually reach the target tissues. This is the case for dietary lecithin, a source of PUFA-containing phospholipids that mediate an increase in lipid peroxidation and platelet-activating factor bioactivity in the lung ${ }^{(10)}$. A third mechanism involves interaction of luminal contents with mucosal elements. Certain dietary components interacting with the mucosal lymphoid tissue (gut-associated lymphoid tissue; GALT) can modulate the local immune response that, in turn, can modify the immune response of other mucosal lymphoid tissues due to the interconnection of the mucosal immune systems ${ }^{(11)}$. This is the mechanism by which oral bioactive proteins such as colostrum-derived proteins ${ }^{(12)}$ or milk-derived proteins ${ }^{(13,14)}$ modify the peripheral immune responses.

In rats challenged with Staphylococcus aureus enterotoxin $\mathrm{B}$, dietary supplementation with spray-dried plasma proteins (SDP) reduced the mucosal immune response in both the organised and diffused GALT, protecting the gut mucosal lymphoid tissue from excessive activation ${ }^{(15,16,17)}$. SDP can also modulate the mucosal immune response in extra-intestinal tissues; for example, in an epidemiological study of Canadian swine farms, feeding plasma proteins was associated with reduced mortality due to porcine reproductive and respiratory syndrome ${ }^{(18)}$. Other peripheral effects of dietary SDP involve changes in the activation of the pituitary-adrenal axis following an LPS challenge ${ }^{(19)}$ and reduced mRNA expression of TNF- $\alpha$ and IL-1 $\beta$ in the adrenal gland, spleen, hypothalamus, pituitary gland and liver ${ }^{(20)}$.

Since this class of supplements also improves the survival and performance of turkeys during a respiratory challenge stimulated by Pasteurella multocida ${ }^{(21)}$, we investigated the therapeutic potential of plasma supplements in a mouse model of acute lung inflammation, based on the intranasal administration of LPS. Specifically, we studied the innate immune system because this mediates the defence against pathogens and regulates tissue health and integrity ${ }^{(2)}$.

\section{Material and methods}

\section{Animals and diets}

Male C57BL/6 mice were supplied by Harlan Ibérica (Barcelona, Spain) and kept under stable temperature and humidity conditions, with a $12 \mathrm{~h}$ light $-12 \mathrm{~h}$ dark cycle and free access to food and water. All protocols used in the present study were approved by the Ethics Committees for Animal Experimentation of the University of Barcelona (Barcelona, Spain) and the Catalan government. The animals were weaned at day 19 after birth, distributed at random in groups of seven to eight mice (two to three animals per cage) and fed the experimental diets for 2 weeks. This time period was adequate for plasma supplements to demonstrate their effect on immune response. The mice were monitored for food intake and body weight throughout the experimental period. Dietary treatments included (1) control: mice fed the control diet; (2) SDP: mice fed a diet with $8 \%$ SDP; (3) Ig concentrate (IC): mice fed a diet with $2 \%$ IC (provided the same amount
Table 1. Composition of experimental diets

\begin{tabular}{|c|c|c|c|}
\hline Ingredient & Control & $\operatorname{SDP}(g / k g)$ & IC \\
\hline Spray-dried animal plasma $\left(\mathrm{SDP}^{\star}\right)$ & - & 80 & - \\
\hline Ig fraction concentrate $(\mathrm{IC} \dagger)$ & - & - & 20 \\
\hline Maize starch & 199 & $308 \cdot 8$ & $223 \cdot 6$ \\
\hline Skimmed milk & 531 & 340.5 & $486 \cdot 7$ \\
\hline Sugar & 94.5 & 94.5 & 94.5 \\
\hline Soyabean oil & 70 & 70 & $69 \cdot 6$ \\
\hline Cellulose & 50 & 50 & 50 \\
\hline AIN-93 GM & 35 & 35 & 35 \\
\hline AIN-93 VX‡ & 15 & 15 & 15 \\
\hline DL-Methionine & 2.5 & $3 \cdot 2$ & $2 \cdot 6$ \\
\hline Choline bitartrate & 3 & 3 & 3 \\
\hline Total & 1000 & 1000 & 1000 \\
\hline
\end{tabular}

SDP, spray-dried plasma, IC, Ig concentrate.

* SDP from porcine blood (AP-820; APC-Europe S.A., Granollers, Spain).

† APC-Europe S.A.

‡ Provided by Harlan Ibérica (Barcelona, Spain).

of Ig as the SDP diet); (4) LPS: mice fed a control diet and challenged with LPS; (5) LPS-SDP: mice fed the diet with 8\% SDP and given LPS; (6) LPS-IC: mice fed the diet with $2 \%$ IC and treated with LPS.

SDP is a feed ingredient obtained by centrifuging blood from healthy pigs, and IC is obtained by removing most of the albumin from plasma, resulting in a fraction containing approximately $40 \% \mathrm{Ig}^{(22)}$. Both ingredients were spray-dried to obtain a stable powder. Maintenance of the native structure of the protein was confirmed by immunoelectrophoresis and Western blotting ${ }^{(23)}$. The diets were balanced for energy and total $\mathrm{N}$, and lysine and methionine were formulated to meet the National Research Council requirements ${ }^{(24)}$ for laboratory animals (Table 1). The $\mathrm{N}$ content of the control diet was adjusted with milk protein. All diets were prepared by Harlan Ibérica.

\section{Lipopolysaccharide challenge}

LPS from Escherichia coli (O128:B12; Sigma-Aldrich, St Louis, MO, USA) was dissolved in PBS $(625 \mu \mathrm{g} / \mathrm{ml})$. The mice (16-18g body weight) were anaesthetised with isofluorane on day 33 (for $24 \mathrm{~h}$ sampling) or on day 34 of life (for $6 \mathrm{~h}$ sampling), and were administered $10 \mu$ l of the LPS solution (or PBS) in each nostril. To collect bronchoalveolar lavage fluid (BALF), lung and blood for analysis of the lymphocytes ( $24 \mathrm{~h}$ after the LPS treatment) or cytokines ( 6 and $24 \mathrm{~h}$ after LPS), the mice were anaesthetised by intraperitoneal administration of ketamine $(80 \mathrm{mg} / \mathrm{kg})$ and xylazine $(6 \mathrm{mg} / \mathrm{kg})$. Blood was withdrawn by cardiac puncture. At the end of the experiment, the mice were killed by cervical dislocation. The samples used for protein and RNA determinations were immediately frozen with liquid $\mathrm{N}_{2}$ and stored at $-80^{\circ} \mathrm{C}$.

\section{Bronchoalveolar lymphocytes}

Bronchoalveolar lavage was performed by the intra-tracheal instillation of $1 \mathrm{ml} \mathrm{PBS}^{(25)}$. The BALF was recovered (0.8$0.9 \mathrm{ml}$ ) and centrifuged at $950 \mathrm{~g}$ for $10 \mathrm{~min}$, and the pelleted BALF cells were re-suspended in PBS-FBS. The cells were 
counted, and viability was determined with a solution of acridine orange and ethidium bromide. In all cases, cell viability was higher than $95 \%$. The supernatant was frozen at $-80^{\circ} \mathrm{C}$ for further analysis.

\section{Lung lymphocytes}

Once BALF was obtained, the samples of the lung tissue were excised for protein, cell isolation and mRNA determinations. The lung lymphocytes were isolated according to Woolard et $a l^{(25)}$. Briefly, the lung tissue was washed and later was finely minced and incubated in Roswell Park Memorial Institute (RPMI) 1640 (Invitrogen, Carlsbad, CA, USA) with $5 \%$ FBS, $100000 \mathrm{U} / 1$ penicillin, $100 \mathrm{mg} / \mathrm{l}$ streptomycin, $10 \mathrm{~mm}$-HEPES, $2 \mathrm{nM}$-L-glutamine and $150 \mathrm{U} / \mathrm{ml}$ collagenase (Invitrogen). After incubation for $90 \mathrm{~min}$ at $37^{\circ} \mathrm{C}$ in an automatic shaker, the remaining intact tissue was disrupted by passage through a 21-gauge needle. The suspension was centrifuged at $600 \mathrm{~g}$ for $7 \mathrm{~min}$ at $4^{\circ} \mathrm{C}$. The supernatant was discarded, and the pellet was suspended in $40 \%$ Percoll (GE Healthcare Bio-Sciences, Little Chalfont, Bucks, UK) layered onto $80 \%$ Percoll and centrifuged at $600 \boldsymbol{g}$ for $20 \mathrm{~min}$ at $15^{\circ} \mathrm{C}$. The cells at the interface were collected, washed in RPMI-1640 with FCS, HEPES and penicillin/streptomycin, and suspended in PBS-FBS. The cells were counted, and viability was determined as described earlier. In all cases, cell viability was higher than $75 \%$.

\section{Blood lymphocytes}

After cervical dislocation, the blood was drawn by cardiac puncture with a heparinised syringe and mixed with $7 \mathrm{ml}$ of erythrocyte lysing buffer $\left(0.17 \mathrm{M}-\mathrm{NH}_{4} \mathrm{Cl}, 0.01 \mathrm{M}-\mathrm{KHCO}_{3}\right.$, $0 \cdot 1 \mathrm{~mm}$-EDTA, adjusted at $\mathrm{pH} 7 \cdot 3$ ). This solution remained at room temperature for $5 \mathrm{~min}$ and was then centrifuged at $300 \mathrm{~g}$ for $5 \mathrm{~min}$ at $25^{\circ} \mathrm{C}$. The cells obtained from the pellet were washed with PBS-FBS and centrifuged at $300 \boldsymbol{g}$ for $5 \mathrm{~min}$ at $4^{\circ} \mathrm{C}$. The supernatant was discarded, and the cells were suspended in the same solution.

\section{Cell staining}

The cells $\left(3 \times 10^{4}\right.$ for the BALF samples and $1.5 \times 10^{5}$ for the lung and blood samples) were incubated with primary mouse monoclonal antibodies for $30 \mathrm{~min}$ at $4{ }^{\circ} \mathrm{C}$. The primary antibodies used were anti-CD45 APC-A750 (eBioscience, Inc., San Diego, CA, USA) for leucocytes; lymphocytes and non-lymphocytic leucocytes were separated by forward/side scatter; anti-CD68 A700 (eBioscience, Inc.) for monocytes, anti-Ly6G FITC (BD Pharmingen, Franklin Lakes, NJ, USA) for neutrophils, anti-CD14 PE (eBioscience, Inc.) for activated neutrophils/monocytes; and isotype control. The samples were subsequently washed in PBS-FBS and centrifuged at $600 \mathrm{~g}$ for $6 \mathrm{~min}$ at $4^{\circ} \mathrm{C}$. Finally, the washed cells were fixed with $400 \mu \mathrm{l}$ of $4 \% \mathrm{w} / \mathrm{v}$ paraformaldehyde and stored at $4{ }^{\circ} \mathrm{C}$ until analysis. The samples were analysed in a BD FACSAria ${ }^{\mathrm{TM}}$ Flow Cytometer at the Cytometry Unit of the Scientific and Technical Support Services of the University of Barcelona.

\section{Lung homogenate}

The samples were homogenised in a lysis buffer containing 0.1 mm-EDTA, $0 \cdot 1 \mathrm{~mm}$-ethylene glycol tetraacetic acid, $1 \%$ Triton and $2 \%$ protease inhibitor cocktail (Sigma-Aldrich). The homogenate was centrifuged at $4^{\circ} \mathrm{C}$ at $14000 \mathrm{~g}$ for $10 \mathrm{~min}$. The IL-10 was determined in the supernatant (see later). The amount of protein in the lung homogenate and supernatant was assayed by the Bio-Rad protein assay (BioRad, Hercules, CA, USA).

\section{Cytokine and chemokine assays}

The cytokines determined were IL- $1 \alpha$, IL-1 $\beta$, TNF- $\alpha$, IL-6, granulocyte-macrophage colony-stimulating factor (GM-CSF) and granulocyte CSF (G-CSF). The chemokines CCL2, CCL3, CCL4 and CXCL1 were studied by means of the Bio-Plex Mouse Cytokine Panel (Bio-Rad) in samples of BALF supernatants from animals killed 6 and $24 \mathrm{~h}$ after the LPS challenge. The cytokine IL-10 was studied in samples of the lung homogenate with the Bio-Plex Mouse Cytokine Assay (Bio-Rad). The detection limits were $0.8 \mathrm{pg} / \mathrm{ml}$ for IL- $1 \alpha ; 5.8 \mathrm{pg} / \mathrm{ml}$ for IL- $1 \beta ; 12 \mathrm{pg} / \mathrm{ml}$ for TNF- $\alpha ; 1.4 \mathrm{pg} / \mathrm{ml}$ for IL- $6 ; 8.1 \mathrm{pg} / \mathrm{ml}$ for GM-CSF; $2.3 \mathrm{pg} / \mathrm{ml}$ for G-CSF; $6.4 \mathrm{pg} / \mathrm{ml}$ for CCL2; $13 \mathrm{pg} / \mathrm{ml}$ for CCL3; $2.7 \mathrm{pg} / \mathrm{ml}$ for CCL4; and $1.6 \mathrm{pg} / \mathrm{ml}$ for CXCL1. The detection limit for IL-10 was $2 \cdot 1 \mathrm{pg} / \mathrm{ml}$.

\section{RNA extraction and RT}

Frozen samples of lung tissue taken from animals $6 \mathrm{~h}$ after the LPS challenge were disrupted mechanically, and total RNA was extracted with TRIzol (Invitrogen) following the manufacturer's instructions. Extracted RNA was treated with RQ1 RNase-free DNAase (Promega, Inc., Madison, WI, USA) and reverse transcribed with Superscript ${ }^{\mathrm{TM}}$ III RT (Invitrogen) using an oligo-(dT) 20 primer, according to the supplier's protocol (Invitrogen).

\section{Real-time PCR}

Complementary DNA served as a template in a $20 \mu \mathrm{l}$ reaction volume containing $0.2 \mu \mathrm{mol} / 1$ of each primer: inducible $\mathrm{NO}$ synthase (iNOS), forward: 5'-GGC AAC ATC AGG TCG GCC ATC AC-3', reverse: 5'-CGT ACC GGA TGA GCT GTG AAT T-3' (122 bp); glyceraldehyde-3-phosphate dehydrogenase (GAPDH), forward: 5'-GGC ATT GCT CTC AAT GAC AA-3', reverse: $5^{\prime}$-CCC TGT TGC TGT AGC CGT AT-3' (73bp) and $2 \mathrm{x} \mathrm{SyBr}^{\circledR}$ GreenER SuperMix (Invitrogen). Real-time PCR was performed in an ABI Prism 7000 Sequence Detection System (Applied Biosystems, Carlsbad, CA, USA). The PCR conditions were as described previously ${ }^{(26)}$

\section{Statistical analysis}

All results are expressed as means with their standard errors. The effects of LPS and diets (and their interaction) on leucocyte populations and on iNOS expression were analysed by two-way factorial ANOVA, followed by the Bonferroni

\footnotetext{
Technical Support Services of the University of Barcelona.
} 
(A)

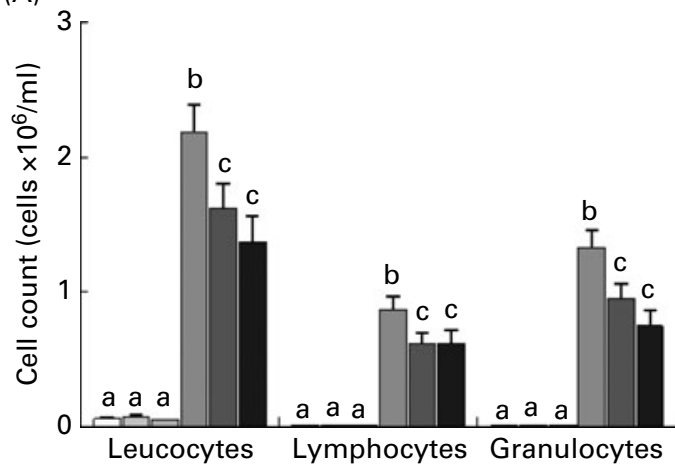

(B)

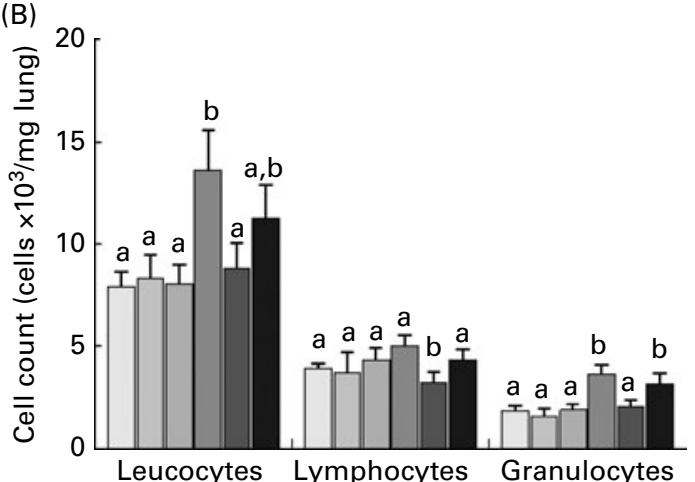

Fig. 1. Cell count in (A) bronchoalveolar lavage fluid and (B) lung tissue in control ( $\square$ ), spray-dried plasma (SDP, $\square$ ), Ig concentrate (IC, $\square$ ), lipopolysaccharide (LPS, $\square$ ), LPS-SDP ( $\square$ ) and LPS-IC ( $\square$ ) mice. Values are means, with their standard errors represented by vertical bars, $n$ 7-8. (A) The LPS effect, the diet effect and the interaction between diet and LPS were significant in the three cell types $(P<0.001, P<0.05$ and $P<0.05$, respectively). (B) The LPS effect was significant in leucocytes and granulocytes $(P=0.018)$; the diet effect was significant in the three cell types $(P<0.05)$; the interaction between diet and LPS administration was significant only in lymphocytes $(P<0.05)$. ${ }^{a, b, c}$ Mean values with unlike letters were significantly different $(P<0.05)$

post hoc test. Cytokine and chemokine concentrations were analysed by three-way ANOVA (LPS challenge, time, diet and their interactions), followed by the Bonferroni post hoc test, using SPSS 14.0 software (SPSS, Inc., Chicago, IL, USA). Differences were considered significant at $P<0 \cdot 05$.

\section{Results}

\section{Leucocyte counts and cell populations}

Intra-nasal administration of LPS induced an immune response in BALF, lung tissue and blood that was consistent and reproducible, and with low variability. In the lung airways, there was massive leucocyte recruitment (thirty-fivefold increase in BALF; $P<0.001$; Fig. $1(\mathrm{~A}))$, which was reduced by $25 \%$ by SDP $(P<0.05)$ and by $37 \%$ by IC $(P<0.05)$. LPS administration increased the recruitment of the lymphocytes and non-lymphocytic leucocytes into the lung airways $(P<0 \cdot 05)$, and both were significantly reduced by SDP and IC (Fig. 1(A)).

In control mice, the majority of BALF non-lymphocytic leucocytes was monocytes (94.3\%), while only $2.6 \%$ were neutrophils (Table 2). This profile was reversed by LPS since the neutrophil population became several-fold higher than the monocyte population, and this cellular shift was not affected by dietary treatment. LPS also increased 3.5-fold the percentage of activated neutrophils and twentyfold the population of activated monocytes. Both SDP and IC supplements reduced the percentage of activated neutrophils, but only SDP prevented in part monocyte activation in the challenged mice (Table 2)

In the lung tissue, LPS increased leucocyte recruitment by $30 \%$ (Fig. 1(B)), and this effect was completely prevented by SDP supplementation. However, the effects of LPS on the relative distribution of leucocyte subsets (Table 2) were not modified by the plasma supplements. Interestingly, both supplements reduced the percentage of monocytes and neutrophils in the unchallenged groups. As to the degree of activation of these cells, LPS increased the percentage of activated neutrophils almost threefold and that of activated monocytes over thirtyfold, whereas dietary supplements did not modify this response.
In the blood, LPS induced a leucocyte distribution profile similar to that observed in the lung tissue, i.e. an increase in the percentage of activated neutrophils and monocytes (tenfold and threefold, respectively), which were partially inhibited by both plasma supplements (Table 2).

\section{Chemokine and cytokine}

Chemokine and cytokine expression is presented in Figs. 2 and 3 , respectively. Although most of the variables showed maximal responses at $6 \mathrm{~h}$, there were still significant differences $24 \mathrm{~h}$ after the LPS challenge. In general, the response to LPS was a several-fold increase in the expression of cytokines and chemokines, both 6 and $24 \mathrm{~h}$ after the challenge.

The effect of LPS on chemokines at $6 \mathrm{~h}$ was significant, especially on the expression of CCL3 (a more than 1000-fold increase; Fig. 2). At $24 \mathrm{~h}$, the response was still significant. Dietary treatment reduced chemokine production at both $6 \mathrm{~h}$ (CCL2, CCL3 and CCL4) and at 24h (CCL3 and CCL4, Fig. 2).

For cytokines, the highest response was obtained for IL-6, TNF- $\alpha$ and G-CSF (more than 1000-fold increase; Fig. 3), and the response at $6 \mathrm{~h}$, with the exception of IL- $1 \alpha$, was higher than at $24 \mathrm{~h}$. Both dietary treatments were effective in reducing cytokine concentration, including an $80 \%$ reduction in TNF- $\alpha$ and a $30 \%$ reduction in IL- $1 \alpha$ expression. In spite of increased variability in cytokine concentrations $24 \mathrm{~h}$ after LPS challenge, both dietary treatments reduced the levels of IL$1 \alpha$ and TNF- $\alpha$ (Fig. 3). The expression of IL-10 in the lung tissue is shown in Fig. 4. LPS had no effect on its concentration in the tissue, but both SDP and IC supplements stimulated its expression in the challenged mice.

\section{Inducible NO synthase expression}

In the lung tissue, LPS increased iNOS expression by $13 \%$ (LPS group, 1.13 (SEM 0.03); control group, 1.00 (SEM 0.02); $P<0.05)$, and this effect was removed by both the SDP and IC supplements (LPS-SDP, 0.99 (SEM 0.04) and LPS-IC, 1.02 (SEM 0.02); both $P<0.05$ ). 
Table 2. Populations of neutrophils and monocytes in bronchoalveolar lavage fluid (BALF), lung and blood after $24 \mathrm{~h}$ administration in control, spraydried plasma (SDP), Ig concentrate (IC), lipopolysaccharide (LPS), LPS-SDP and LPS-IC mice

(Mean values with their standard errors, $n 7-8$ )

\begin{tabular}{|c|c|c|c|c|c|c|c|c|c|c|}
\hline & \multirow{2}{*}{$\begin{array}{l}\text { LPS } \\
\text { challenge }\end{array}$} & \multicolumn{2}{|c|}{ Control diet } & \multicolumn{2}{|c|}{ SDP diet } & \multicolumn{2}{|c|}{ IC diet } & \multirow{2}{*}{$\begin{array}{c}\text { LPS effect } \\
P \\
\end{array}$} & \multirow{2}{*}{$\begin{array}{c}\text { Diet effect } \\
P\end{array}$} & \multirow{2}{*}{$\begin{array}{c}\text { LPS } \times \text { diet } \\
\text { interaction } \\
P\end{array}$} \\
\hline & & Means & SEM & Means & SEM & Means & SEM & & & \\
\hline \multicolumn{11}{|l|}{ BALF (\%) } \\
\hline \multicolumn{11}{|c|}{ Non-lymphocytic leucocytes } \\
\hline Neutrophils & No & $2 \cdot 6$ & 0.2 & $2 \cdot 0$ & 0.2 & 3.2 & 0.5 & \multirow{2}{*}{$<0.001$} & \multirow{2}{*}{ NS } & \multirow{2}{*}{ NS } \\
\hline & Yes & $69 \cdot 7$ & $7 \cdot 1$ & $71 \cdot 8$ & 3.9 & $81 \cdot 4$ & $2 \cdot 7$ & & & \\
\hline \multirow[t]{2}{*}{ Monocytes } & No & 94.3 & 0.7 & 94.7 & 0.8 & $93 \cdot 7$ & 0.9 & \multirow{2}{*}{$<0.001$} & \multirow[b]{2}{*}{ NS } & \multirow{2}{*}{ NS } \\
\hline & Yes & $9 \cdot 3$ & $2 \cdot 4$ & $9 \cdot 1$ & 0.6 & 8.7 & 1.4 & & & \\
\hline \multicolumn{11}{|l|}{ Neutrophils } \\
\hline Activated & No & $24 \cdot 0^{\mathrm{a}}$ & 5.5 & $18 \cdot 5^{\mathrm{b}}$ & 4.4 & $17 \cdot 4^{b}$ & $1 \cdot 8$ & \multirow{2}{*}{$<0.001$} & \multirow[b]{2}{*}{0.048} & \multirow[b]{2}{*}{ NS } \\
\hline Neutrophils & Yes & $84 \cdot 2^{\mathrm{a}}$ & $1 \cdot 1$ & $78 \cdot 1^{b}$ & 3.7 & $75 \cdot 7^{b}$ & 3.7 & & & \\
\hline \multicolumn{11}{|l|}{ Monocytes } \\
\hline Activated & No & 0.8 & 0.2 & 0.6 & 0.2 & $0 \cdot 6$ & 0.1 & \multirow{3}{*}{$<0.001$} & \multirow{3}{*}{0.042} & \multirow[b]{2}{*}{0.049} \\
\hline Monocytes & Yes & $16 \cdot 3^{a}$ & $2 \cdot 0$ & $9 \cdot 7^{\mathrm{b}}$ & 1.3 & $13 \cdot 7^{\mathrm{a}, \mathrm{b}}$ & 3.3 & & & \\
\hline \multicolumn{9}{|c|}{ Lung $(\%)$} & & \\
\hline Non-lymphocyt & & & & & & & & & & \\
\hline Neutrophils & No & $18 \cdot 3^{a}$ & 0.5 & $14 \cdot 8^{b}$ & 0.9 & $15 \cdot 1^{b}$ & 1.3 & & & \\
\hline & Yes & $29 \cdot 4$ & 1.5 & 32.5 & $3 \cdot 2$ & $29 \cdot 7$ & $4 \cdot 1$ & $<0.001$ & NS & 0.038 \\
\hline Monocytes & No & $19 \cdot 1^{a}$ & $2 \cdot 4$ & $12 \cdot 2^{\mathrm{b}}$ & 1.3 & $13 \cdot 4^{\mathrm{b}}$ & 1.7 & & & \\
\hline & Yes & $32 \cdot 1$ & 3.9 & 28.7 & 3.3 & 32.6 & $4 \cdot 1$ & $<0.001$ & NS & $0 \cdot 017$ \\
\hline Neutrophils & & & & & & & & & & \\
\hline Activated & No & $2 \cdot 1$ & 0.6 & 1.0 & 0.2 & 0.8 & 0.2 & & & \\
\hline Neutrophils & Yes & 5.4 & $1 \cdot 1$ & $7 \cdot 2$ & $2 \cdot 0$ & $7 \cdot 2$ & $2 \cdot 0$ & $<0.001$ & NS & NS \\
\hline Monocytes & & & & & & & & & & \\
\hline Activated & No & 0.5 & $0 \cdot 2$ & 0.3 & $0 \cdot 1$ & $1 \cdot 1$ & 0.4 & & & \\
\hline Monocytes & Yes & $17 \cdot 4$ & 3.7 & $16 \cdot 6$ & 4.8 & $17 \cdot 7$ & 3.8 & $<0.001$ & NS & NS \\
\hline Blood (\%) & & & & & & & & & & \\
\hline Non-lymphocyt & & & & & & & & & & \\
\hline Neutrophils & No & $15 \cdot 7^{\mathrm{a}}$ & 0.7 & $8 \cdot 3^{\mathrm{b}}$ & 0.7 & $8.9^{b}$ & 0.6 & & & \\
\hline & Yes & $16 \cdot 2^{a}$ & 1.9 & $9 \cdot 3^{b}$ & 1.3 & $13 \cdot 6^{b}$ & 1.3 & 0.034 & $<0.001$ & NS \\
\hline Monocytes & No & $19 \cdot 7$ & $1 \cdot 1$ & $16 \cdot 6$ & $2 \cdot 1$ & $16 \cdot 6$ & 1.9 & & & \\
\hline & Yes & 51.6 & $6 \cdot 3$ & $56 \cdot 5$ & $4 \cdot 2$ & $48 \cdot 1$ & $4 \cdot 7$ & $<0.001$ & NS & NS \\
\hline Neutrophils & & & & & & & & & & \\
\hline Activated & No & $0.32^{\mathrm{a}}$ & 0.03 & $0.57^{b}$ & 0.09 & $0.67^{b}$ & 0.09 & & & \\
\hline Neutrophils & Yes & $3 \cdot 5^{a}$ & 0.7 & $1 \cdot 5^{\mathrm{b}}$ & 0.4 & $1 \cdot 8^{\mathrm{b}}$ & 0.5 & $<0.001$ & NS & 0.019 \\
\hline Monocytes & & & & & & & & & & \\
\hline Activated & No & $1.0^{\mathrm{a}}$ & 0.2 & $1.0^{\mathrm{a}}$ & $0 \cdot 1$ & $1 \cdot 7^{\mathrm{b}}$ & 0.2 & & & \\
\hline Monocytes & Yes & $3 \cdot 2^{a}$ & 0.5 & $1.9^{\mathrm{b}}$ & 0.4 & $1 \cdot 4^{\mathrm{b}}$ & 0.2 & $<0.001$ & NS & 0.001 \\
\hline
\end{tabular}

${ }^{\mathrm{a}, \mathrm{b}}$ Mean values within a row with unlike superscript letters were significantly different $(P<0.05)$.

\section{Discussion}

Dietary spray-dried plasma proteins are widely used in farm animal nutrition because they maintain normal intestinal barrier function and growth performance ${ }^{(27)}$. They also have anti-inflammatory effects as they attenuate the mucosal inflammatory response in the small intestine of rats exposed to a staphylococcal enterotoxin ${ }^{(28,29)}$; in humans, bovine immunoglobulin concentrates reduce the clinical effects of cryptosporidiosis with $\operatorname{AIDS}^{(30)}$.

In addition to its effects on gut homeostasis, which involve modulation of GALT $^{(28)}$, animal plasma supplements can also affect lymphoid tissue populations and the expression of cytokines in peripheral tissues, such as the spleen and the liver ${ }^{(20)}$, and in the lungs ${ }^{(21)}$. These observations have led to the hypothesis that dietary plasma supplements may also be effective in modulating the response of the immune cells in the non-intestinal mucosal tissues such as the nasopharyngeal mucosa (nasal and bronchoalveolar-associated lymphoid tissue). This hypothesis is sustained by the existence of the common mucosal immune system that connects the inductive sites (here the GALT) with the effector sites (nasal and bronchoalveolar-associated lymphoid tissue) for the generation of T lymphocyte responses ${ }^{(11)}$.

The study was done during the post-weaning period, because at this stage the mucosal immune system is still immature and therefore more susceptible to infection ${ }^{(31)}$; furthermore, we had demonstrated in rats that plasma supplements are already effective in this early period ${ }^{(17)}$. In the mouse model of acute lung inflammation induced by LPS, the pulmonary response is characterised by lymphocyte migration and the massive release of pro-inflammatory cytokines and chemokines, which recruit monocytes and neutrophils into the lung airway and into the lung tissue ${ }^{(9,32)}$. We were primarily interested in the effects of SDP and IC on the innate immune response because of its triple role: first, mediating the defence against pathogens; secondly, detecting tissue damage, and finally, regulating tissue health and integrity ${ }^{(2)}$.

The main finding of the present study is that dietary supplementation with SDP or IC reduces the innate immune response to LPS inhalation. The reduction in leucocyte counts in BALF and the lung tissue, the lower concentration 

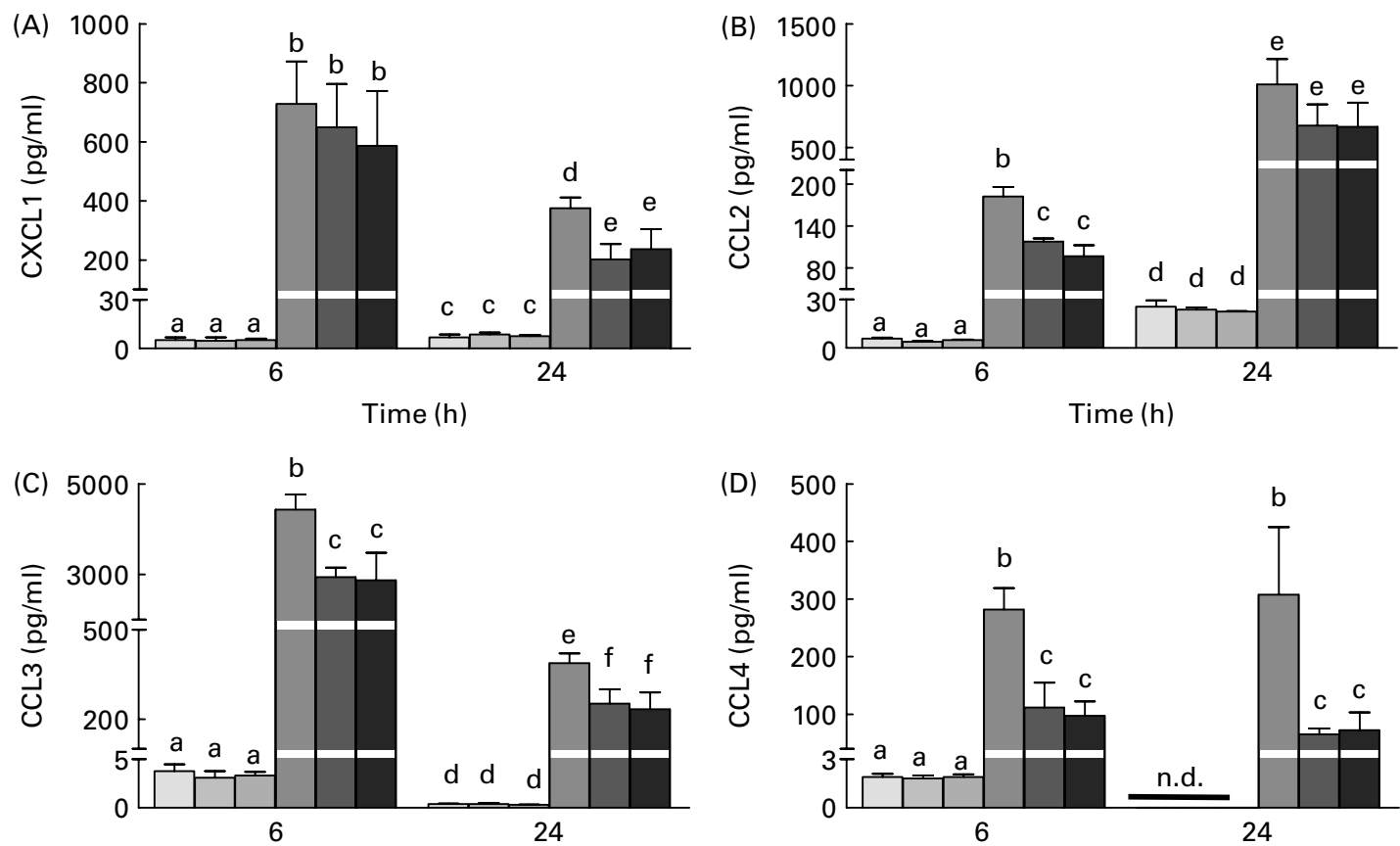

Time (h)

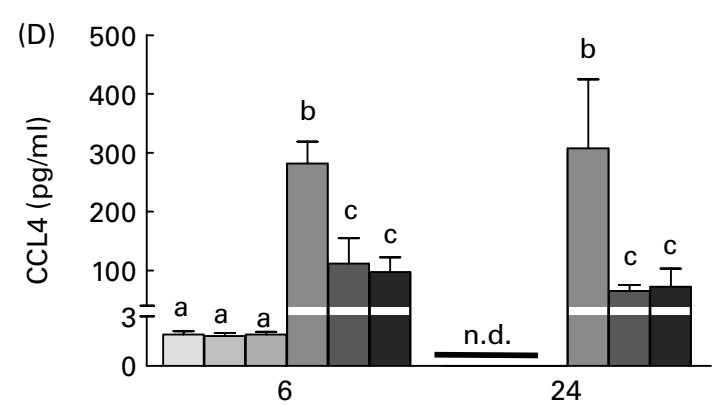

Time (h)

Fig. 2. Concentration of (A) CXCL1, (B) CCL2, (C) CCL3 and (D) CCL4 in the supernatant of bronchoalveolar lavage fluid from control ( $\square$ ), spray-dried plasma (SDP, $\square$ ), Ig concentrate (IC, $\square$ ), lipopolysaccharide (LPS, $\square$ ), LPS-SDP $(\square)$ and LPS-IC ( $\square$ ) mice 6 and $24 \mathrm{~h}$ after the LPS challenge. n.d., Not determined. Values are means, with their standard errors represented by vertical bars, $n 5-6$. The LPS effect was significant in the four chemokines studied $(P \leq 0.001)$; the diet effect was significant for CCL2 and CCL3 $(P<0.05)$; the time effect was significant except for CCL4 $(P<0.001)$; the interaction between diet and LPS was significant for CCL2 and CCL3 $(P<0.05)$; the interaction between LPS and time was significant for all the chemokines except for CCL4 $(P<0.005)$. ${ }^{a-f}$ Mean values with unlike letters were significantly different $(P<0.05)$.

of pro-inflammatory cytokines and chemokines in BALF, and the lower iNOS expression in the lung tissue, all suggest a dietary-dependent reduction in the chemical mediators responsible for acute lung injury. These results agree with previous observations in rats indicating that dietary plasma proteins protect the intestine from immune overstimulation caused by the intraperitoneal administration of $S$. aureus enterotoxin $\mathrm{B}^{(17)}$. The mechanism of action involves a reduction in the pro-inflammatory to anti-inflammatory cytokine ratios in both Peyer's patches and the mucosa ${ }^{(26)}$.
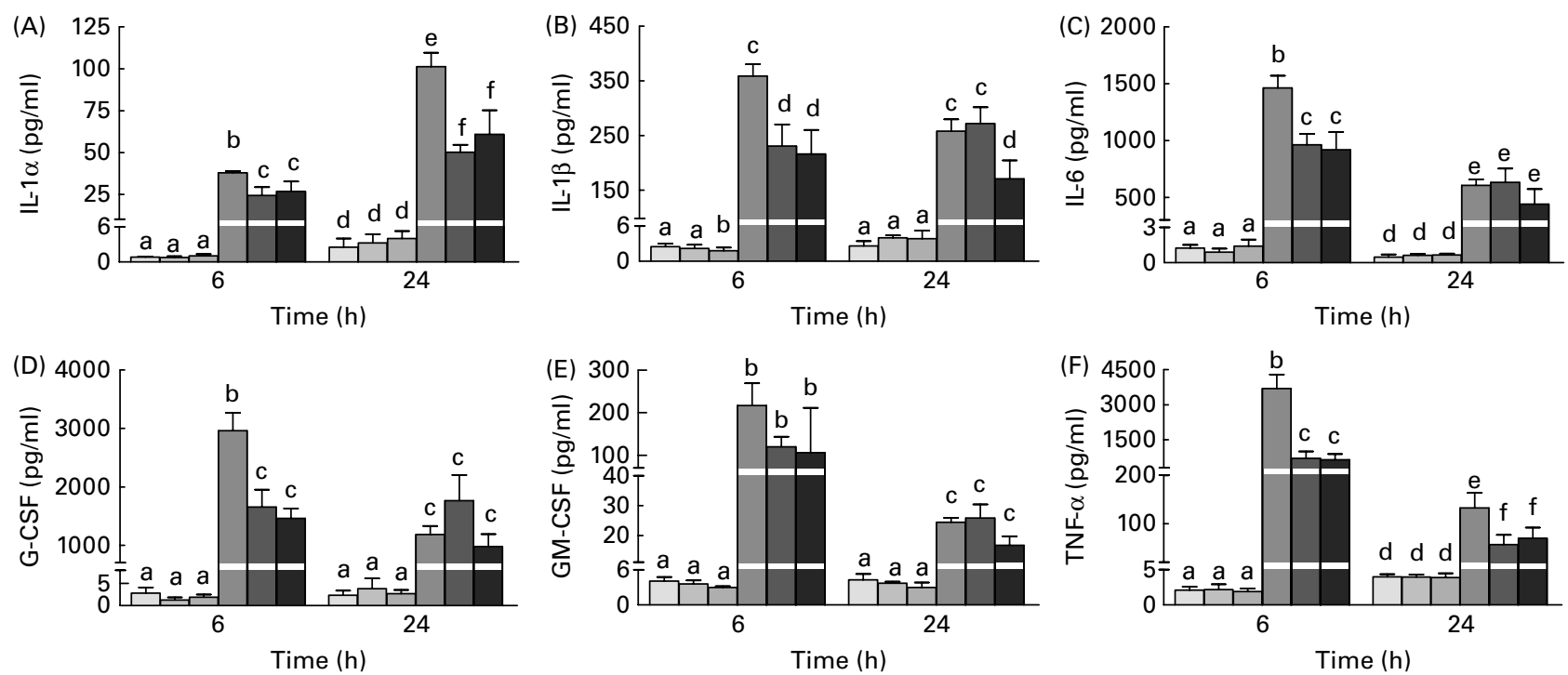

Fig. 3. Concentration of (A) IL-1 $\alpha$, (B) IL-1 $\beta$, (C) IL-6, (D) G-CSF, (E) GM-CSF and (F) TNF- $\alpha$ in the supernatant of bronchoalveolar lavage fluid from control ( $\square$ ), spray-dried plasma (SDP, $\square$ ), Ig concentrate (IC, $\square$ ), lipopolysaccharide (LPS, $\square$ ), LPS-SDP ( $\square$ ) and LPS-IC ( $\square$ ) mice 6 and $24 \mathrm{~h}$ after the LPS challenge. Values are means, with their standard errors represented by vertical bars, $n 5-6$. The LPS effect was significant in the six cytokines studied $(P<0.001)$; the diet effect was significant for IL-1 $\alpha$, IL-1 $\beta$, IL-6 and G-CSF $(P \leq 0.039)$ and for TNF- $\alpha(P<0.001)$; the time effect was significant except for IL-1 $\beta(P \leq 0.010)$; the interaction between diet and LPS was significant for IL-1 $\alpha$, IL-1 $1 \beta$, IL-6 and G-CSF $(P \leq 0.05)$ and for TNF- $\alpha(P<0.001)$; the interaction between LPS and time was significant for all the cytokines except for IL-1 $\beta(P \leq 0.010) .{ }^{a-f}$ Mean values with unlike letters were significantly different $(P<0.05)$. 


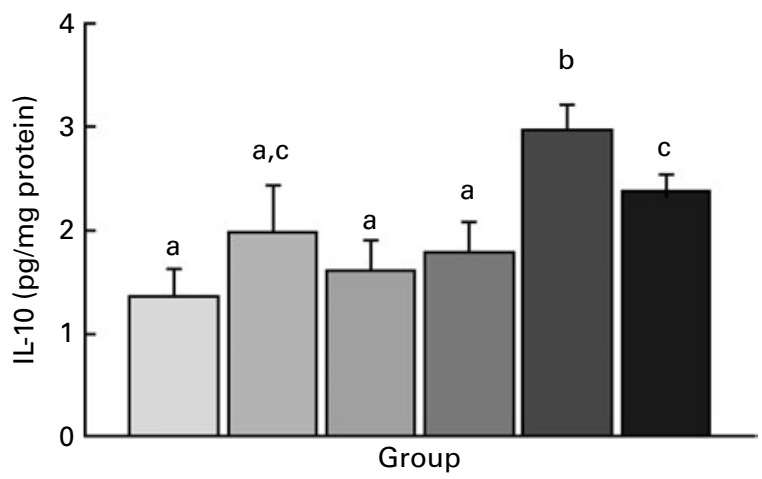

Fig. 4. Concentration of IL-10 in lung tissue from control $(\square)$, spray-dried plasma (SDP, $\square$ ), Ig concentrate (IC, $\square$ ), lipopolysaccharide (LPS, $\square$ ), LPS-SDP ( $\square$ ) and LPS-IC ( $\square$ ) mice $6 \mathrm{~h}$ after the LPS challenge. Values are means, with their standard errors represented by vertical bars, $n$ 5-6. ${ }^{a, b, c}$ Mean values with unlike letters were significantly different $(P<0.05)$.

In mice that were not exposed to LPS, the number of leucocytes recruited into the airway was low, with a clear predominance of monocytes, and a very low amount of neutrophils. The LPS challenge increased cell recruitment to the airway space; specifically, the percentage of neutrophils increased by $70 \%$. These findings are consistent with the results reported by Reutershan et al ${ }^{(32)}$ who used a similar model. The primary function of neutrophils in the innate immune response is to contain and kill invading microbial pathogens $^{(3)}$, and their concentration in BALF is a maximal $24 \mathrm{~h}$ after LPS administration ${ }^{(32)}$. In BALF and the lung tissue, LPS increased the proportion of activated neutrophils (threeand twofold, respectively) and of activated monocytes (twenty- and thirty-fourfold, respectively), as a consequence of the release of large amounts of chemokines, in agreement with the previous observations ${ }^{(9)}$. The effects of LPS on leucocyte counts in BALF were attenuated by SDP and IC, indicating lower cell infiltration, consistent with reduced eosinophil infiltration and lower degree of degranulation observed in the intestine of rats challenged with $S$. aureus enterotoxin $\mathrm{B}^{(28)}$. Both the plasma supplements reduced the percentage of activated neutrophils and monocytes in the lung airway; therefore, lower cell migration and smaller activation of inflammatory cells to the pulmonary tissue may reduce the potential damage to the respiratory epithelium and vascular endothelium associated with the inflammatory response.

The main effects of dietary supplementation with plasma proteins were observed in the lung airway, but there were also marked effects in the lung tissue and in peripheral blood. It is noteworthy that there is a reduction in the resident monocytes and neutrophils in the lung tissue, which implies a reduction in the normal pro-inflammatory state associated with the mucosal system ${ }^{(33)}$. At a systemic level, both diets decreased the percentage of activated monocytes and activated neutrophils induced by LPS, consistent with the reduction in the percentage of activated monocytes and activated neutrophils in the lung airway observed in the plasma-supplemented mice. The finding that diet reduces the activation of neutrophils and monocytes is important, because these populations are involved in the acute lung injury induced by $\operatorname{LPS}^{(34)}$.
Inhaled LPS increased cytokine and chemokine concentration as well as iNOS expression in the lung tissue and in BALF, in agreement with the previous observations ${ }^{(9)}$. Moreover, pro-inflammatory cytokines can alter the structure of the respiratory and vascular epithelia, which compromise the gas exchange. For example, excess TNF- $\alpha$ enhances the paracellular permeability of microvascular endothelial cells leading to tissue dysfunction and shock ${ }^{(35)}$. The present results show that LPS increased TNF- $\alpha$ concentration in BALF at $6 \mathrm{~h}$, reaching a concentration 1700 -fold higher than in the controls, which dropped to only sixtyfold $24 \mathrm{~h}$ after the challenge, consistent with the previous reports ${ }^{(36)}$. The concentration in BALF of the other pro-inflammatory cytokines studied was also dramatically increased at $6 \mathrm{~h}$, confirming the observations of Yeh et al. ${ }^{(9)}$ and partly prevented by both SDP and IC. The effects of SDP and IC on GM-CSF expression may be of special significance, because it plays an important role in the pathogenesis of acute and chronic lung disease ${ }^{(37)}$

Since chemokines attract leucocytes into tissues, they are good indicators of the inflammatory state. CCL2 recruits monocytes, lymphocytes and basophils, and activates mast cells and basophils ${ }^{(38)}$. The pattern of the response of chemokines in BALF was similar to that of cytokines, i.e. most of them (CXCL1 and CCL3) showed an acute response that was greater at $6 \mathrm{~h}$ than at $24 \mathrm{~h}$, whereas CCL2 was much more evident at $24 \mathrm{~h}$ after the challenge. Both SDP and IC attenuated the LPS-induced increase in chemokine concentration, and this effect is relevant due to the role of chemokines as inducers of cell migration into the bronchoalveolar space during inflammation.

The mechanism of action of dietary functional proteins is not well understood. Spray-dried plasma contains biologically active peptides and functional proteins including Ig (IgA, IgG and IgM), albumin and growth factors ${ }^{(23)}$. These proteins show special efficacy when the animals are exposed to environmental or immunological challenges. The IC supplement lacks most of the albumin fraction, and therefore it contains higher amounts of $\gamma$-globulins. Although it has been suggested that IgG is responsible for the SDP effects ${ }^{(39)}$, the contribution of other active plasma components to the functional effects of plasma supplements should also be considered. Plasma contains over 250 active peptides ${ }^{(40)}$ that retain most of their biological activity after spray drying ${ }^{(23)}$. The main effects of SDP and IC involve regulation of mucosal GALT, which may be the result of reduced mucosal binding of luminal antigens mediated by plasma glycoproteins ${ }^{(39)}$. GALT regulation can also be ascribed to changes in the profile of the gut microflora ${ }^{(41)}$ or to the biological activity of other plasma components either interacting with luminal extensions of dendritic cells or crossing the epithelium across $\mathrm{M}$ cells or through tight-junction complexes. Although the interaction of SDP and IC with the intestinal mucosa is not yet clarified, it is well demonstrated that plasma supplements modulate the expression of pro-inflammatory cytokines in the GALT of pigs $^{(42)}$ and rats ${ }^{(26)}$. Our studies in the rat model of mild intestinal inflammation ${ }^{(29)}$ indicate that the mechanism by which plasma supplements reduce GALT activation may also involve profile modulation of cytokines ${ }^{(26)}$. 
Cuzzocrea et $a l .{ }^{(43)}$ have shown that IL-10 has also an important role during acute lung inflammation, inhibiting the release of pro-inflammatory mediators such as IL-6 ${ }^{(44)}$ and $\mathrm{iNOS}^{(45)}$. In contrast to the mild response induced by $S$. aureus enterotoxin B in the intestine, the effects of LPS in the lung are characterised by increased leucocyte recruitment and strongly enhanced cytokine and chemokine production. However, even in this acute inflammatory condition, both SDP and IC inhibited the immune response, indicating that dietary modulation of intestinal lymphocyte proliferation ${ }^{(17)}$ and cytokine expression ${ }^{(26)}$ can reduce inflammatory responses in distant regions, albeit interconnected by the common mucosal immune system. The analysis of IL-10 in the lung tissue showed that both SDP and IC supplements can significantly increase its expression, supporting the view that the peripheral anti-inflammatory effects of plasma supplements also involve modulation of the cytokine ratios.

In conclusion, dietary SDP or IC interacts with the immune cells of GALT and reduces the pulmonary response to an LPS challenge, consistent with the hypothesis that there is extensive communication between the mucosal tissues through the common mucosal immune system. The present results support the view that oral intervention with plasma protein supplements is a new strategy for preventing, managing and attenuation of lung inflammation.

\section{Acknowledgements}

The present study was supported by grant RDITCRD07-1-008 (Generalitat de Catalunya, Barcelona, Spain). The research group is also supported by grant 2009SGR0471 for Consolidated Research Groups (Generalitat de Catalunya). Mò. M., L. M. and Mi. M. reported no conflicts of interest; A. P.-B. and J. P. are employed by APC-Europe S.A. (Granollers, Spain); L. R., Joy C. and Joe C. are employed by APC, Inc., Ankelny, IA, USA; E. W. is employed by Proliant Health and Biologicals, Ankeny, IA, USA. The authors' contributions were as follows: Mi. M., J. P., L. R., Joy C., E. W., Joe C. and A. P.-B. designed the study; A. P.-B., Mò. M. and L. M. conducted the study; J. P. provided the essential materials; A. P.-B., Mò. M. and Mi. M. analysed the data and wrote the manuscript; Mò. M., J. P., L. R., Joy C., E. W., Joe C., Mi. M. and A. P.-B. discussed the results. All authors read and approved the final manuscript.

\section{References}

1. Augusto LA, Li J, Synguelakis M, et al. (2002) Structural basis for interactions between lung surfactant protein $\mathrm{C}$ and bacterial lipopolysaccharide. J Biol Chem 277, 23484-23492.

2. Chaudhuri N \& Sabroe I (2008) Basic science of the innate immune system and the lung. Paediatr Respir Rev 9, $236-242$.

3. Nathan C (2006) Neutrophils and immunity: challenges and opportunities. Nat Rev Immunol 6, 173-182.

4. Hazlewood LC, Wood LG, Hansbro PM, et al. (2010) Dietary lycopene supplementation suppresses Th2 response and lung eosinophilia in a mouse model of allergic asthma. J Nutr Biochem 22, 95-100.
5. Wheeler MD, Rose ML, Yamashima S, et al. (2000) Dietary glycine blunts lung inflammatory cell influx following acute endotoxin. Am J Physiol Lung Cell Mol Physiol 279, L390-L398.

6. Melchior D \& Sève B (2008) Dietary tryptophan helps to preserve tryptophan homeostasis in pigs suffering from lung inflammation. J Anim Sci 86, 3473-3479.

7. Pontes-Arruda A, Demichele S, Seth A, et al. (2008) The use of an inflammation-modulating diet in patients with acute lung injury or acute respiratory distress syndrome: a metaanalysis of outcome data. JPEN J Parenter Enteral Nutr 32 , 596-605.

8. Xie YC, Dong XW, Wu XM, et al. (2009) Inhibitory effects of flavonoids extracted from licorice on lipopolysaccharide-induced acute pulmonary inflammation in mice. Int Immunopharmacol 9, 194-200.

9. Yeh CC, Lin CC, Wang SD, et al. (2007) Protective and immunomodulatory effect of Gingyo-san in a murine model of acute lung inflammation. J Ethnopharmacol 111, 418-426.

10. Muehlmann LA, Zanatta AL, Farias CL, et al. (2010) Dietary supplementation with soybean lecithin increases pulmonary PAF bioactivity in asthmatic rats. J Nutr Biochem 21, $532-537$.

11. Kiyono H \& Fukuyama S (2004) NALT- versus Peyer's patchmediated mucosal immunity. Nat Rev Immunol 4, 699-710.

12. Lilius EM \& Marnila P (2001) The role of colostral antibodies in prevention of microbial infections. Curr Opin Infect Dis 14, 295-300.

13. Cross ML \& Gill HS (2000) Immunomodulatory properties of milk. Br J Nutr 84, S81-S89.

14. Gill HS, Doull F, Rutherfurd KJ, et al. (2000) Immunoregulatory peptides in bovine milk. Br J Nutr 84, S111-S117.

15. Pérez-Bosque A, Amat C, Polo J, et al. (2006) Spray-dried animal plasma prevents the effects of Staphylococcus aureus enterotoxin B on intestinal barrier function in weaned rats. J Nutr 136, 2838-2843.

16. Pérez-Bosque A, Miró L, Polo J, et al. (2008) Dietary plasma proteins modulate the immune response of diffuse gutassociated lymphoid tissue in rats challenged with Staphylococcus aureus enterotoxin B. J Nutr 138, 533-537.

17. Pérez-Bosque A, Pelegrí C, Vicario M, et al. (2004) Dietary plasma protein affects the immune response of weaned rats challenged with Staphylococcus aureus superantigen B. J Nutr 134, 2667-2672.

18. Dewey CE, Johnston WT, Gould L, et al. (2006) Postweaning mortality in Manitoba swine. Can J Vet Res 70, 161-167.

19. Carroll JA, Touchette KJ, Matteri RL, et al. (2002) Effect of spray-dried plasma and lipopolysaccharide exposure on weaned pigs: II. Effects on the hypothalamic-pituitaryadrenal axis of weaned pigs. J Anim Sci 80, 502-509.

20. Touchette KJ, Carroll JA, Allee GL, et al. (2002) Effect of spray-dried plasma and lipopolysaccharide exposure on weaned pigs: I. Effects on the immune axis of weaned pigs. J Anim Sci 80, 494-501.

21. Campbell JM, Quigley JD III, Russell LE, et al. (2004) Efficacy of spray-dried bovine serum on health and performance of turkeys challenged with Pasteurella multocida. J Appl Poult Sci Res 13, 388-393.

22. Lee Y-Z, Sim JS, Al-Mashikhi S, et al. (1998) Separation of immunoglobulins from bovine blood by polyphosphate precipitation and chromatography. J Agric Food Chem 36, 922-928.

23. Borg BS, Capmbell JM \& Polo J, et al. (2002) Evaluation of the chemical and biological characteristics of spray-dried plasma protein collected from various locations around the 
world. Proceedings of 33rd Annual Meeting of the American of Swine Veterinarians, pp. 97-100. Kansas City, Missouri.

24. NRC (1995) Nutrient Requirements of Laboratory Animals, 4th ed. Washington, DC: National Academy Press.

25. Woolard MD, Huding D, Tabor L, et al. (2005) NK cells in gamma-interferon-deficient mice suppress lung innate immunity against Mycoplasma spp. Infect Immun 73, 6742-6751.

26. Pérez-Bosque A, Miró L, Polo J, et al. (2010) Dietary plasma protein supplements prevent the release of mucosal proinflammatory mediators in intestinal inflammation in rats. J Nutr 140, 25-30.

27. Campbell JM, Polo J, Russell LE, et al. (2010) Review of spray-dried plasma's impact on intestinal barrier function. Livest Sci 133, 239-241.

28. Moretó M \& Pérez-Bosque A (2009) Dietary plasma proteins, the intestinal immune system and the barrier functions of the intestinal mucosa. J Anim Sci 87, E92-E100.

29. Pérez-Bosque A \& Moretó M (2010) A rat model of mild intestinal inflammation induced by Staphylococcus aureus enterotoxin B. Proc Nutr Soc 69, 447-453.

30. Greenberg PD \& Cello JP (1996) Treatment of severe diarrhea caused by Cryptosporidium parvum with oral bovine immunoglobulin concentrate in patients with AIDS. J Acquir Immune Defic Syndr Hum Retrovirol 13, 348-354.

31. Bailey M, Haverson K, Inman C, et al. (2005) The development of the mucosal immune system pre- and post-weaning: balancing regulatory and effector function. Proc Nutr Soc 64, 451-457.

32. Reutershan J, Basit A, Galkina EV, et al. (2005) Sequential recruitment of neutrophils into lung and bronchoalveolar lavage fluid in LPS-induced acute lung injury. Am J Physiol Lung Cell Mol Physiol 289, L807-L815.

33. Suzuki T, Chow CW \& Downey GP (2008) Role of innate immune cells and their products in lung immunopathology. Int J Biochem Cell Biol 40, 1348-1361.

34. Schuh K \& Pah A (2009) Inhibition of the MAP kinase ERK protects from lipopolysaccharide-induced lung injury. Biochem Pharmacol 77, 1827-1834.
35. Tracey KJ \& Cerami A (1994) Tumor necrosis factor- $\alpha$ : a pleiotropic cytokine and therapeutic target. Annu Rev Med 45, 491-503.

36. Larsson R, Rocksén D, Lilliehöök B, et al. (2000) Dose-dependent activation of lymphocytes in endotoxininduced airway inflammation. Infect Immun 68, 6962-6969.

37. Puljic R, Benediktus E, Plater-Zyberk C, et al. (2007) Lipopolysaccharide-induced lung inflammation is inhibited by neutralization of GM-CSF. Eur J Pharmacol 557, 230-235.

38. Puneet P, Moochhala S \& Bhatia M (2005) Chemokines in acute respiratory distress syndrome. Am J Physiol Lung Cell Mol Physiol 288, L3-L15.

39. Van Dijk AJ, Niewold TA, Nabuurs MJ, et al. (2002) Small intestinal morphology and disaccharidase activities in early-weaned piglets fed a diet containing spray-dried porcine plasma. J Vet Med A Physiol Pathol Clin Med 49, 81-86.

40. Anderson NL \& Anderson NG (2002) The human plasma proteome: history, character, and diagnostic prospects. Mol Cell Proteomics 1, 845-867.

41. Bhandari SK, Xu B, Nyachoti CM, et al. (2008) Evaluation of alternatives to antibiotics using an Escherichia coli K88+ model piglet diarrhea: effects on gut microbial ecology. J Anim Sci 86, 836-847.

42. Bosi P, Casini L, Finamore A, et al. (2004) Spray-dried plasma improves growth performance and reduces inflammatory status of weaned pigs challenged with enterotoxigenic Escherichia coli K88. J Anim Sci 82, 1764-1772.

43. Cuzzocrea S, Mazzon E, Dugo L, et al. (2002) Absence of endogenous interleukin-10 enhances the evolution of acute lung injury. Eur Cytokine Netw 13, 285-297.

44. Heyen JR, Ye S, Finck BN, et al. (2000) Interleukin (IL)-10 inhibits IL-6 production in microglia by preventing activation of NF-kappaB. Brain Res Mol Brain Res 77, 138-147.

45. Ogando D, Cella M, Ribeiro ML, et al. (2004) IL-10 inhibits nitric oxide synthesis in murine uterus. Neuroimmunomodulation 11, 127-132. 